\title{
Inpatient Treatment for the Middle- aged and Elderly in Central China
}

\section{Yan Jiang ${ }^{1 \dagger}$, Yu Wang ${ }^{1 \dagger}$, Yang $\mathrm{Li}^{1}$, Yuming Zhang ${ }^{1}$, Yinjun Zhao ${ }^{2}$, Xiaojun Wang ${ }^{1}$, Chi Ma ${ }^{3 *}$ and Shuangge $\mathrm{Ma}^{1,2 *}$}

${ }^{1}$ Center for Applied Statistics, School of Statistics, Renmin University of China, Beijing, China, ${ }^{2}$ School of Public Health, Yale

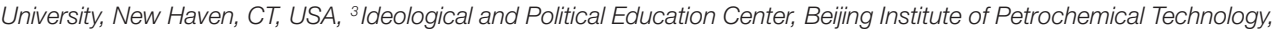
Beijing, China

Background: Compared to outpatient treatment and self-treatment, inpatient treatment corresponds to more severe illness and poses more serious health and financial burden to patients. The goal of this study is to provide an updated and comprehensive description of the prevalence, characteristics, and cost of inpatient treatment for the middle-aged and elderly in Central China, which is highly populated, less-developed, and agriculture-dominating.

Edited by:

Mihajlo (Michael) Jakovljevic, University of Kragujevac, Serbia;

Hosei University Tokyo, Japan

Reviewed by: Nemanja Rancic, University of Defence, Serbia Kuangnan Fang, Xiamen University, China

*Correspondence: Chi Ma machi.bipt@gmail.com; Shuangge Ma shuangge.ma@yale.edu

tThese authors have contributed equally to this work.

Specialty section: This article was submitted to Health Economics, a section of the journal

Frontiers in Public Health

Received: 22 December 2016

Accepted: 17 January 2017

Published: 02 February 2017

Citation:

Jiang Y, Wang Y, Li Y, Zhang Y, Zhao $Y$, Wang $X, M a C$ and Ma $S$ (2017) Inpatient Treatment for the Middle-aged and Elderly in Central China.

Front. Public Health 5:7. doi: 10.3389/fpubh.2017.00007
Methods: A survey was conducted in August 2013 in the Henan province. Data on 1,464 subjects were collected.

Results: Among the surveyed subjects, 582 had at least one episode of inpatient treatment. Subjects with different inpatient treatment status differ in the distributions of age, education, occupation, area, health insurance coverage, physical condition, and presence of chronic disease. The surveyed subjects had up to six inpatient treatments within 12 months. Different episodes have different characteristics. Age and the presence of chronic disease are significantly associated with the number of inpatient treatments. The utilization of grade III hospital for inpatient treatment is associated with gender, marital status, and per capita income. The total and out-of-pocket costs are associated with education, utilization of type III hospital, and insurance utilization.

Conclusion: This study has provided a comprehensive description of inpatient treatment for Central China, an area with low developmental and economic status. The observations may assist improving health conditions and disease treatment for this less-advantaged area.

Keywords: inpatient treatment, middle-aged and elderly, characteristics, prevalence, cost, China

\section{INTRODUCTION}

The development of China's healthcare system falls far behind its economic achievements (1). A system-wide reform took place in 2009, with the goal of improving quality and accessibility of healthcare and reducing cost (2). Studies have been conducted, investigating multiple aspects of

Abbreviations: OOP, out-of-pocket; aOR, adjusted odds ratio. 
China's healthcare system, including the reform, health insurance coverage and utilization, hospital management, cost, medication, and others (3-5).

China has a large aging population. It is projected that by 2050, the older population will make up a quarter of its total population. The middle-aged and elderly face fast deteriorating health conditions and increasing medical cost, and their health care is of special importance. When facing illness, a person may choose from inpatient treatment, outpatient treatment, and selftreatment. Inpatient treatment is defined as an appointment, procedure, and/or treatment requiring an overnight stay in a health facility. It usually corresponds to more severe illness conditions and poses a more serious health and financial threat.

Health cost has been an important topic and been studied in China as well as in many other countries (6-10). In previous studies, many efforts have been contributed to investigate medical costs and the associated factors for middle-aged and elderly people in China. Jiang and others studied the access to health care and the medical expenditure for the subjects aged 45 years and above who were randomly selected in mainland China (5). Wang and others investigated characteristics associated with insurance utilization and the association of treatment cost and insurance utilization for the middle-aged and elderly people with samples randomly collected in mainland China (11). For medical expenditure, associated factors that have been identified include demographic characteristics, such as age, gender, education and occupation, insurance status, living area, and so on (12-16). However, all the above studies do not have enough evidence to quantify the results specifically for middle-aged and elderly population who have inpatient treatment. Also, characteristics and effects of inpatient treatment in Central China have received less attention.

The goal of this study is to provide an updated and comprehensive description of inpatient treatment for the middle-aged and elderly (45 years old and above) in Central China. China is a large country with significant spatial variations. Of special interest is the highly populated, less-developed, and agriculturedominating Central China. This area has a lower socioeconomic status and lower quality of health care, and as a result, illness may have more serious consequences. This study complements the existing literature along the following aspects. First, it focuses on inpatient treatment, which has characteristics significantly different from the other types of treatments. As inpatient treatment corresponds to more serious illness, it is more important from a healthcare perspective. Second, it comprehensively characterizes multiple aspects of inpatient treatment, including prevalence, characteristics, and cost. In contrast, most of the existing studies have focused on only a single aspect. Third, it focuses on the middle-aged and elderly, whose health care deserve more attention. Fourth, unlike many published studies, it is not limited to the treatment of a specific type of illness. Fifth, most of the existing studies were based on databases constructed by the central and local governments or hospitals. Such databases are designed to describe inpatient treatment from the healthcare providers' perspective. Instead, in this study, data were collected using survey and can better describe inpatient treatment from the patients' perspective. In addition, the survey also collected data on subjects without inpatient treatment for comparison. Such data are not available in hospital databases. Last, quite a few studies analyzed data collected on or before 2008. The reform launched in 2009 has fundamentally changed the healthcare system, and there is a strong need for an updated data collection and analysis.

\section{MATERIALS AND METHODS}

\section{Data Collection}

The survey was conducted in August 2013. Samples were collected in the Henan province, which is the largest province in and representative of Central China. It is one of the least developed areas in China, highly populated, and agriculture-dominating. The study was approved by the Research Ethics Review Committee at the Renmin University of China.

At the beginning of each survey, the interviewer introduced the nature of the survey. Each interviewee was asked to sign an informed consent form. Information was collected to determine inclusion. An interviewee was excluded if he/she refused to participate, was younger than 45 years, or could not provide reliable information on illness conditions and expenditure. A total of 1,464 subjects finished the survey, with a response rate of $68 \%$. The main reasons for refusal included "not comfortable with disclosing certain information," "no time to finish survey," and "concerns over how the results will be presented." For over $95 \%$ of the non-responders, basic demographic information was collected. Analysis suggested comparability of the responders and non-responders.

The survey collected demographic and personal information, including gender, age, marital status, education, occupation, area (rural or urban), physical condition, income, presence of chronic disease, and health insurance coverage and utilization. To measure the accessibility of health care, information was collected on the distance to the nearest hospital and its type (17). Data were collected on all episodes of inpatient treatment during a period of 12 months prior to the survey. For each episode, data were collected on (a) illness leading to treatment, (b) distance to the hospital for treatment (which may differ from the nearest one) and its type, (c) reason(s) for choosing the specific hospital, (d) days of hospitalization, (e) treatment outcome, (f) cost (which includes cost of treatment, transportation/food/accommodation, medicine/supplies, unofficial gift, and lost income. The amount of insurance reimbursement, if insurance was utilized, was also collected.), (g) sources used to finance the cost (income, savings, funds from relatives and friends, and other sources), and (h) whether insurance was utilized. Cost was denominated in the unit RMB (100EUR $=819 \mathrm{RMB}$ by the exchange rate on 1 st August 2013).

\section{Data Analysis}

The subjects' characteristics for the whole cohort and subgroups stratified by the number of inpatient treatments were summarized. Subjects with different inpatient treatment status were compared. $p$ Values were computed from chi-squared tests for categorical variables and $t$ tests for continuous variables. Summary characteristics of inpatient treatment were described 
for all episodes combined and for the first to sixth episodes of each subject. Multivariate analyses were conducted, controlling for confounders. The first set of multivariate analysis is on the frequency of inpatient treatment. Of special interest is the contrast between those with at least two inpatient treatments and those with only one. Logistic regression analysis was conducted, and the adjusted odds ratios (aOR) and $p$-values were conducted. The second set of analysis is on the pursuit of health care. Specifically, we analyzed whether grade III hospitals were used for treatment. The dominating majority of hospitals in China are public and under a unified grading system, with grade III hospitals providing the best quality of care and also being the most expensive (18). A binary variable was created to indicate whether a grade III hospital was used for treatment. Logistic regression analysis was conducted, and the odds ratios and their significance levels were computed. The third set of analysis is on the cost of inpatient treatment (for those with at least one episode). The first type of cost is the total cost, defined as the sum of cost on treatment, transportation/food/accommodation, medicine/supplies, unofficial gifts (to doctors and nurses), and lost income (due to illness). The second is the out-of-pocket (OOP) cost defined as the total cost minus insurance reimbursement. Linear regression was conducted. The estimated regression coefficients and their significance level were computed. Analysis was conducted using S-Plus Version 8.2 (TIBCO Software Inc.).

\section{RESULTS}

\section{Sample Characteristics}

The results are shown in Table 1. A total of 582 subjects had at least one inpatient treatment, and 160 had more than one. In the comparison of patients' characteristics of those with and without inpatient treatment, the age distribution is significantly different $(p<0.001)$, with those having inpatient treatments being older. The distribution of education is also significantly different ( $p=0.007$ ). For example, $20.7 \%$ in the group of no inpatient treatment had senior high school, compared to $15.3 \%$ in the group having inpatient treatment. Another significant variable is occupation $(p=0.009)$. Those with inpatient treatments are more likely to be from urban $(59.6 \%$ versus $50.3 \%, p<0.001)$ and have insurance (99.3\% versus $97.7 \%, p=0.02$ ). In addition, they are more likely to have bad physical conditions $(p<0.001)$ and chronic diseases $(p<0.001)$. In the comparison of those with two or more inpatient treatments against those with one, age, physical condition, and presence of chronic disease are significant. The observed patterns are similar to those in the first set of comparison.

\section{Characteristics of Inpatient Treatment Episodes}

The 582 subjects had a total of 823 episodes of inpatient treatments (Table 2). The numbers of subjects with 1-6 episodes are 582, $160,51,16,10$, and 4 , respectively. With small counts, statistics for the fourth to sixth episodes are less reliable. $98.4 \%$ of the episodes were treated in public hospitals with the majority of which being in grade II (45.7\%) and III (40.4\%) hospitals. The distributions across the first three episodes are similar. The average distance to hospital is about $56 \mathrm{~km}$. Multiple factors contributed to the choice of hospital, with the most common concern being the quality of treatment (58.8\%), followed by easy-to-use insurance (38.0\%) and close distance (36.0\%). The average days of hospitalization is 17.8 , and a decreasing trend across treatments is observed $(18.5,16.7$, and 15.2 days for the first to third treatments). The outcomes are mostly positive, with $14.0 \%$ cured and $79.8 \%$ getting better. The distributions differ across treatments. For example, 16.3\%, 10.7\%, and $5.9 \%$ were cured for the first to third episodes, respectively. The average gross total cost is about 14,478RMB. The largest cost category is treatment, followed by lost income, transportation/ food/accommodation, and medicine/supplies. The average insurance payment is $5,521 \mathrm{RMB}$, and the average OOP cost is $9,260 \mathrm{RMB}$. In terms of financing, $65.2 \%$ was funded by income, followed by funds from relatives and friends (20.6\%) and savings (11.4\%). Differences are observed across episodes. Insurance was used for the majority of the episodes (93.6\%).

Multiple illness conditions led to inpatient treatment. The most common is cardiovascular and cerebrovascular diseases (36.8\%), followed by stomach and digestive diseases (10.9\%), hypertension (7.7\%), and others. Many other conditions, such as cervical spine diseases and trauma fractures, also led to inpatient treatments, but are less common.

\section{Frequency of Inpatient Treatment}

In analysis, 32 records with missing measurements are removed, leading to an effective sample size of 550. The results are shown in Table 3. The association for age is significant. With the 45- to 50-year group as reference, the 51-60, 61-70, and 70+ age groups have aORs 2.472, 2.517, and 4.46, respectively. In addition, the presence of chronic disease is significant, with an aOR 4.229 $(p=0.024)$.

\section{Utilization of Grade III Hospitals}

Different treatment episodes have different characteristics (Table 2). In this analysis, we focus on the first episodes of all subjects. Analysis on the rest five episodes is not conducted with a sample size consideration. Three records with missing measurements are removed, leading to an effective sample size of 579. The analysis results are shown in Table 4. Those being female (aOR 1.594, $p=0.024$ ), being married (aOR 2.266, $p=0.004$ ), and having a higher income $(\mathrm{aOR} 1.014, p=0.047)$ are more likely to use grade III hospitals.

\section{Cost of Treatment}

The multivariate analysis results are presented in Table 5. As above, analysis is conducted on the first episodes of all subjects. Removing records with missing measurements leads to effective sample sizes of 548 and 508, respectively, for total and OOP cost. In the analysis of total cost, education is significant. With no schooling as the baseline, those with senior high and junior college and more spent 11.9 K RMB $(p=0.018)$ and 13.6 K RMB ( $p=0.048)$ more, respectively. The type of hospital used for treatment is also significant. With grade I hospital as the baseline, subjects using grade III hospital spent $12.6 \mathrm{~K}$ RMB more $(p=0.003)$. Another significant variable is insurance utilization. 
TABLE 1 | Characteristics for the whole cohort and the subgroups stratified by the number of inpatient treatment.

\begin{tabular}{|c|c|c|c|c|c|c|c|}
\hline & Total $(n=1,464)$ & $\begin{array}{c}\text { Inpatient } \\
\text { treatment }=0 \\
(n=882)\end{array}$ & $\begin{array}{c}\text { Inpatient } \\
\text { treatment }>0 \\
(n=582)\end{array}$ & $p$ & $\begin{array}{c}\text { Inpatient } \\
\text { treatment = } 1 \\
(n=422)\end{array}$ & $\begin{array}{c}\text { Inpatient } \\
\text { treatment } \geq 2 \\
(n=160)\end{array}$ & $p$ \\
\hline Gender & & & & 0.081 & & & 0.088 \\
\hline Male & $626(42.8)$ & 361 (40.9) & $265(45.5)$ & & $183(43.4)$ & $82(51.3)$ & \\
\hline Female & $838(57.2)$ & $521(59.1)$ & $317(54.5)$ & & $239(56.6)$ & $78(48.8)$ & \\
\hline Age & $62.4 \pm 10.7$ & $61.0 \pm 10.5$ & $64.5 \pm 10.6$ & $<0.001$ & $63.3 \pm 10.5$ & $67.7 \pm 10.4$ & $<0.001$ \\
\hline Age group & & & & $<0.001$ & & & $<0.001$ \\
\hline $45-50$ & $254(17.3)$ & $181(20.5)$ & $73(12.5)$ & & $64(15.2)$ & $9(5.6)$ & \\
\hline $51-60$ & $423(28.9)$ & $284(32.2)$ & $139(23.9)$ & & $103(24.4)$ & $36(22.5)$ & \\
\hline $61-70$ & $452(30.9)$ & 255 (28.9) & $197(33.8)$ & & $148(35.1)$ & 49 (30.6) & \\
\hline$>70$ & $335(22.9)$ & $162(18.4)$ & $173(29.7)$ & & $107(25.4)$ & $66(41.3)$ & \\
\hline Marital status & & & & 0.175 & & & 0.806 \\
\hline Single/divorced/widowed & $250(17.1)$ & $141(16.0)$ & $109(18.7)$ & & $78(18.5)$ & $31(19.4)$ & \\
\hline Married & $1,213(82.9)$ & $740(84.0)$ & $473(81.3)$ & & $344(81.5)$ & $129(80.6)$ & \\
\hline Education & & & & 0.007 & & & 0.455 \\
\hline No schooling & 235 (16.2) & $143(16.3)$ & $92(15.9)$ & & $66(15.8)$ & $26(16.4)$ & \\
\hline Primary & $411(28.2)$ & $220(25.1)$ & $191(33.1)$ & & $130(31.1)$ & $61(38.4)$ & \\
\hline Junior high & $438(30.1)$ & $269(30.6)$ & 169 (29.3) & & $130(31.1)$ & $39(24.5)$ & \\
\hline Senior high & $270(18.6)$ & $182(20.7)$ & $88(15.3)$ & & $65(15.6)$ & $23(14.5)$ & \\
\hline Junior college and above & $101(6.9)$ & $64(7.3)$ & $37(6.4)$ & & $27(6.5)$ & $10(6.3)$ & \\
\hline Occupation & & & & 0.009 & & & 0.109 \\
\hline Governments & $74(5.1)$ & $49(5.6)$ & $25(4.3)$ & & $19(4.5)$ & $6(3.8)$ & \\
\hline Enterprises & $65(4.4)$ & $38(4.3)$ & $27(4.6)$ & & $14(3.3)$ & $13(8.1)$ & \\
\hline Farmers & $551(37.6)$ & $351(39.8)$ & $200(34.4)$ & & $154(36.5)$ & $46(28.8)$ & \\
\hline Small private business & $53(3.6)$ & $38(4.3)$ & $15(2.6)$ & & $13(3.1)$ & $2(1.3)$ & \\
\hline Othera & 47 (3.2) & 34 (3.9) & $13(2.2)$ & & $10(2.4)$ & $3(1.9)$ & \\
\hline Retired & $450(30.7)$ & $245(27.8)$ & 205 (35.2) & & $144(34.1)$ & $61(38.1)$ & \\
\hline No jobs & $224(15.3)$ & $127(14.4)$ & $97(16.7)$ & & $68(16.1)$ & $29(18.1)$ & \\
\hline Area & & & & $<0.001$ & & & 0.150 \\
\hline Urban & $791(54.0)$ & $444(50.3)$ & $347(59.6)$ & & $244(57.8)$ & $103(64.4)$ & \\
\hline Rural & $673(46.0)$ & $438(49.7)$ & $235(40.4)$ & & $178(42.2)$ & $57(35.6)$ & \\
\hline Health insurance coverage & & & & 0.020 & & & \\
\hline Yes & $1,440(98.4)$ & $862(97.7)$ & 578 (99.3) & & $418(99.1)$ & 160 (100.0) & \\
\hline No & $24(1.6)$ & $20(2.3)$ & $4(0.7)$ & & $4(0.9)$ & 0 & \\
\hline $\begin{array}{l}\text { Distance to the nearest hospital } \\
\text { (meter) }\end{array}$ & & & & 0.068 & & & 0.879 \\
\hline$\leq 500$ & $1,061(72.5)$ & $658(74.6)$ & $403(69.2)$ & & $294(69.7)$ & $109(68.1)$ & \\
\hline $501-1,000$ & $236(16.1)$ & $134(15.2)$ & $102(17.5)$ & & $74(17.5)$ & $28(17.5)$ & \\
\hline$\geq 1,001$ & $167(11.4)$ & $90(10.2)$ & $77(13.2)$ & & $54(12.8)$ & $23(14.4)$ & \\
\hline Type of the nearest hospital & & & & 0.065 & & & 0.248 \\
\hline Grade I & $867(59.3)$ & $539(61.2)$ & $328(56.4)$ & & $248(58.8)$ & $80(50.0)$ & \\
\hline Grade II & $413(28.2)$ & 237 (26.9) & $176(30.2)$ & & 119(28.2) & 57 (35.6) & \\
\hline Grade III & $88(6.0)$ & $44(5.0)$ & $44(7.6)$ & & $30(7.1)$ & $14(8.8)$ & \\
\hline Private & $95(6.5)$ & $61(6.9)$ & $34(5.8)$ & & $25(5.9)$ & $9(5.6)$ & \\
\hline $\begin{array}{l}\text { Average personal income (1K } \\
\text { RMB) }\end{array}$ & $12.8 \pm 23.9$ & $12.4 \pm 28.3$ & $13.4 \pm 15.0$ & 0.435 & $13.3 \pm 15.3$ & $13.7 \pm 14.3$ & 0.796 \\
\hline Physical condition & & & & $<0.001$ & & & $<0.001$ \\
\hline Healthy & $346(23.6)$ & $290(32.9)$ & $56(9.6)$ & & $48(11.4)$ & $8(5.0)$ & \\
\hline Just so-so & 655 (44.7) & $416(47.2)$ & $239(41.1)$ & & 191(45.3) & $48(30.0)$ & \\
\hline A little sick & $258(17.6)$ & $113(12.8)$ & $145(24.9)$ & & $102(24.2)$ & $43(26.9)$ & \\
\hline Sick & $168(11.5)$ & $56(6.3)$ & 112 (19.2) & & $69(16.4)$ & $43(26.9)$ & \\
\hline Very sick & $37(2.5)$ & $7(0.8)$ & $30(5.2)$ & & $12(2.8)$ & $18(11.3)$ & \\
\hline Chronic disease & & & & $<0.001$ & & & 0.005 \\
\hline No & $241(16.5)$ & $203(23.0)$ & $38(6.5)$ & & $35(8.3)$ & $3(1.9)$ & \\
\hline Yes & $1,223(83.5)$ & $679(77.0)$ & $544(93.5)$ & & $387(91.7)$ & $157(98.1)$ & \\
\hline Number of inpatient treatment & - & - & $1.4 \pm 0.8$ & & $1.0 \pm 0.0$ & $2.5 \pm 0.9$ & \\
\hline
\end{tabular}

For a categorical variable, count (percentage). For a continuous variable, mean $\pm S D$.

a"Other" means the other occupations except governments, enterprises, farmers, and small private business. 
TABLE 2 | Description of inpatient treatment episodes, for all episodes combined and the first to sixth episodes of each subject.

\begin{tabular}{|c|c|c|c|c|c|c|c|}
\hline & \multirow[t]{2}{*}{ Total $(n=823)$} & \multicolumn{6}{|c|}{ Order of inpatient treatment episode } \\
\hline & & First $(n=582)$ & Second $(n=160)$ & Third $(n=51)$ & Fourth $(n=16)$ & Fifth $(n=10)$ & Sixth $(n=4)$ \\
\hline \multicolumn{8}{|l|}{ Type of hospital } \\
\hline Grade I & $101(12.3)$ & $74(12.8)$ & $23(14.4)$ & $4(7.8)$ & 0 & 0 & 0 \\
\hline Grade II & $375(45.7)$ & 266 (45.9) & $75(46.9)$ & $21(41.2)$ & $9(56.3)$ & $3(30.0)$ & $1(25.0)$ \\
\hline Grade III & $331(40.4)$ & $230(39.7)$ & $61(38.1)$ & $24(47.1)$ & $6(37.5)$ & $7(70.0)$ & $3(75.0)$ \\
\hline Private & $13(1.6)$ & $9(1.6)$ & $1(0.6)$ & $2(3.9)$ & $1(6.3)$ & 0 & 0 \\
\hline Distance to hospital (m) & $\begin{array}{c}56,166.6 \pm \\
437,444.1\end{array}$ & $\begin{array}{l}63,512.2 \pm \\
475,744.5\end{array}$ & $\begin{array}{c}48,212.2 \pm \\
398,863.5\end{array}$ & $\begin{array}{c}21,578.7 \pm \\
72,076.0\end{array}$ & $\begin{array}{c}4,578.1 \pm \\
10,381.7\end{array}$ & $\begin{array}{c}36,875.0 \pm \\
93,347.4\end{array}$ & $\begin{array}{c}1,125.0 \pm \\
250.0\end{array}$ \\
\hline \multicolumn{8}{|c|}{ Reason(s) for choosing the specific hospital } \\
\hline Close distance & 296(36.0) & $197(33.8)$ & $59(36.9)$ & $20(39.2)$ & $13(81.3)$ & $5(50.0)$ & $2(50.0)$ \\
\hline Better treatment & $484(58.8)$ & 345 (59.3) & $94(58.8)$ & $31(60.8)$ & $5(31.3)$ & $6(60.0)$ & $3(75.0)$ \\
\hline Easy-to-use insurance & $313(38.0)$ & $219(37.6)$ & $62(38.8)$ & $16(31.4)$ & $8(50.0)$ & $5(50.0)$ & $3(75.0)$ \\
\hline Easy-to-get appointment & $31(3.8)$ & $19(3.3)$ & $5(3.1)$ & $3(5.9)$ & $2(12.5)$ & $1(10.0)$ & $1(25.0)$ \\
\hline Other & $67(8.1)$ & $54(9.3)$ & $9(5.6)$ & $3(5.9)$ & 0 & $1(10.0)$ & 0 \\
\hline Days of hospitalization & $17.8 \pm 20.2$ & $18.5 \pm 22.2$ & $16.7 \pm 16.9$ & $15.2 \pm 6.8$ & $14.7 \pm 9.9$ & $14.9 \pm 8.8$ & $15.5 \pm 10.2$ \\
\hline \multicolumn{8}{|l|}{ Treatment outcome } \\
\hline Cured & $115(14.0)$ & $95(16.3)$ & $17(10.7)$ & $3(5.9)$ & 0 & 0 & 0 \\
\hline Better & $656(79.8)$ & 455 (78.2) & $129(81.1)$ & $43(84.3)$ & $15(93.8)$ & $10(100.0)$ & $4(100.0)$ \\
\hline Same & $45(5.5)$ & $28(4.8)$ & $12(7.5)$ & $4(7.8)$ & $1(6.3)$ & 0 & 0 \\
\hline Worse & $6(0.7)$ & $4(0.7)$ & $1(0.6)$ & $1(2.0)$ & 0 & 0 & 0 \\
\hline \multicolumn{8}{|l|}{ Cost (RMB) } \\
\hline Treatment & $10,971.2 \pm 22,882.2$ & $11,862.3 \pm 25,886.5$ & $8,597.6 \pm 11,619.3$ & $7,048.4 \pm 6,293.0$ & $9,618.8 \pm 14,093.9$ & $20,300.0 \pm 35,799.8$ & $8,375.0 \pm 2,868.7$ \\
\hline Transportation/food/accommodation & $728.1 \pm 1,842.1$ & $788.3 \pm 2,080.9$ & $528.4 \pm 1,039.6$ & $580.4 \pm 702.0$ & $656.3 \pm 843.8$ & $1,350.0 \pm 2,392.2$ & $575.0 \pm 613.1$ \\
\hline Medicine/supplies & $409.4 \pm 1,766.9$ & $483.9 \pm 2,054.2$ & $228.4 \pm 675.7$ & $269.6 \pm 742.8$ & $187.5 \pm 338.4$ & $100.0 \pm 253.9$ & $250.0 \pm 500.0$ \\
\hline Unofficial gift & $61.0 \pm 625.1$ & $75.7 \pm 738.6$ & $25.7 \pm 133.8$ & $9.8 \pm 70.0$ & $31.3 \pm 125.0$ & $50.0 \pm 158.1$ & $125.0 \pm 250.0$ \\
\hline Lost income & $932.9+3,558.1$ & $966.8+3,724.1$ & $618.6+1,515.3$ & $658.0+1,754.6$ & $2.473 .1+8.979 .8$ & $3.067 .0+7.551 .1$ & $587.5+956.0$ \\
\hline Gross total cost & $14,477.7 \pm 30,194.0$ & $15,100.1 \pm 29,100.9$ & $10,827.3 \pm 14,448.0$ & $8,990.4 \pm 7,726.2$ & $12,929.4 \pm 22,738.4$ & $24,667.0 \pm 45,215.9$ & $120,621.3 \pm 219,852.5$ \\
\hline Paid by insurance & $5,521.5 \pm 9,702.7$ & $6,325.8 \pm 11,151.8$ & $4,862.1 \pm 6,051.5$ & $4,236.6 \pm 3,674.4$ & $5,761.5 \pm 5,369.4$ & $7,555.6 \pm 8,453.7$ & $5,500.0 \pm 3,968.6$ \\
\hline Out-of-pocket cost & $9,260.1 \pm 26,714.6$ & $9,495.5 \pm 23,856.3$ & $6,609.2 \pm 11,213.5$ & $4,950.2 \pm 5,285.5$ & $9,290.0 \pm 20,358.3$ & $18,818.9 \pm 39,848.6$ & $152,661.7 \pm 255,703.0$ \\
\hline \multicolumn{8}{|l|}{ Financial sources } \\
\hline Income & $65.2 \%$ & $67.7 \%$ & $62.1 \%$ & $55.8 \%$ & $48.8 \%$ & $53.0 \%$ & $30.0 \%$ \\
\hline Savings & $11.4 \%$ & $11.6 \%$ & $11.3 \%$ & $11.0 \%$ & $6.9 \%$ & $10.0 \%$ & $20.0 \%$ \\
\hline Funds from relatives/friends & $20.6 \%$ & $17.2 \%$ & $24.9 \%$ & $32.3 \%$ & $44.4 \%$ & $37.0 \%$ & $50.0 \%$ \\
\hline Other & $2.9 \pm 13.8 \%$ & $3.5 \pm 15.5 \%$ & $1.8 \pm 9.0 \%$ & $1.0 \pm 7.0 \%$ & 0 & 0 & 0 \\
\hline \multicolumn{8}{|l|}{ Insurance utilization } \\
\hline Yes & 770 (93.6) & 545 (93.6) & $150(93.8)$ & $46(90.2)$ & 15 (93.8) & $10(100.0)$ & $4(100.0)$ \\
\hline No & $53(6.4)$ & $37(6.4)$ & $10(6.3)$ & $5(9.8)$ & $1(6.3)$ & 0 & 0 \\
\hline
\end{tabular}

For a categorical variable, count (percentage). For a continuous variable, mean $\pm S D$, i.e., confident interval. 
TABLE 3 | Multivariate logistic regression analysis of the number of inpatient treatments: at least two times versus once (reference).

\begin{tabular}{|c|c|c|}
\hline & aOR $(95 \% \mathrm{Cl})$ & $p$ \\
\hline \multicolumn{3}{|l|}{ Gender (reference: male) } \\
\hline Female & $\begin{array}{c}0.829 \\
(0.537-1.281)\end{array}$ & 0.399 \\
\hline \multicolumn{3}{|l|}{ Age group (reference: $45-50$ ) } \\
\hline $51-60$ & $2.472(1.049-5.827)$ & 0.039 \\
\hline $61-70$ & $2.517(1.067-5.939)$ & 0.035 \\
\hline$>70$ & $4.460(1.805-11.017)$ & 0.001 \\
\hline \multicolumn{3}{|c|}{ Marital status (reference: single/divorced/widowed) } \\
\hline Married & $0.980(0.568-1.689)$ & 0.941 \\
\hline \multicolumn{3}{|c|}{ Education (reference: no schooling) } \\
\hline Primary & $1.124(0.612-2.062)$ & 0.707 \\
\hline Junior high & $0.926(0.476-1.800)$ & 0.820 \\
\hline Senior high & $0.915(0.423-1.980)$ & 0.822 \\
\hline Junior college and more & $1.065(0.379-2.991)$ & 0.905 \\
\hline \multicolumn{3}{|c|}{ Occupation (reference: governments) } \\
\hline Enterprises & $2.706(0.732-10.009)$ & 0.136 \\
\hline Farmers & $0.674(0.193-2.353)$ & 0.536 \\
\hline Small private business & $0.522(0.080-3.414)$ & 0.498 \\
\hline Others & $0.960(0.176-5.243)$ & 0.962 \\
\hline Retired & $0.912(0.309-2.688)$ & 0.867 \\
\hline Unemployed & $0.949(0.283-3.186)$ & 0.933 \\
\hline \multicolumn{3}{|l|}{ Area (reference: urban) } \\
\hline Rural & 1.088 (0.579-2.044) & 0.794 \\
\hline \multicolumn{3}{|c|}{ Chronic disease (reference: no) } \\
\hline Yes & $4.229(1.212-14.758)$ & 0.024 \\
\hline \multicolumn{3}{|c|}{ Insurance utilization (reference: yes) } \\
\hline No & $1.852(0.806-4.256)$ & 0.146 \\
\hline Per capita income (1K RMB) & $0.998(0.983-1.013)$ & 0.762 \\
\hline
\end{tabular}

$n=550$ (after removing records with missing measurements).

aOR, adjusted odds ratio.

Not using insurance led to $12.3 \mathrm{~K} \mathrm{RMB}$ more cost $(p=0.024)$. In the analysis of OOP cost, the same set of variables is found to be significant. For education, only the senior high category is significant, with an estimated coefficient of $10.6 \mathrm{~K}(p=0.014)$. Using grade III hospital leads to $9 \mathrm{~K}$ more cost than using grade I hospital $(p<0.001)$. Not using insurance leads to $17.4 \mathrm{~K}$ more cost $(p<0.001)$.

\section{DISCUSSION}

China has a fast aging population. Illness conditions, treatment, and their consequences for the middle-aged and elderly are of significant interest for healthcare providers, researchers, and policy makers. This is especially true for the less-advantaged areas, for example, the highly populated and agriculture-dominating Central China as surveyed in this study.

Using survey, this study is able to better characterize several important aspects of inpatient treatment. Specifically, studies based on hospital databases do not have information on people without treatment, and they are likely to be biased due to the specialty, type, and location of hospitals. In comparison, this study better describes inpatient treatment on the population level. The
TABLE 4 | Analysis on the utilization of grade III hospitals for inpatient treatment.

\section{Using grade III hospital for inpatient treatments} $(n=579)$

\begin{tabular}{llll}
\hline Total & $\begin{array}{l}\text { Using grade III } \\
\text { hospital, } n(\%)\end{array}$ & OR $(p) \quad$ aOR $(p)$
\end{tabular}

\begin{tabular}{lcccc}
\hline $\begin{array}{l}\text { Gender } \\
\text { Male }\end{array}$ & & & & \\
Female & 264 & $99(37.5)$ & - & - \\
\hline Age & 315 & $131(41.6)$ & $1.187(0.317)$ & $1.594(0.024)$ \\
$45-50$ & & & & - \\
$51-60$ & 72 & $23(31.9)$ & - & $0.998(0.996)$ \\
$61-70$ & 137 & $53(38.7)$ & $1.344(0.336)$ & 0 \\
$>70$ & 197 & $81(41.1)$ & $1.488(0.173)$ & $1.145(0.689)$ \\
\hline
\end{tabular}

\section{Marital status}

Single/divorced/

widowed

$\begin{array}{llll}\text { Married } \quad 470 \quad 196(41.7) & 1.578(0.044) & 2.266(0.004)\end{array}$

\section{Education}

No schooling

Primary

Junior high

Senior high

Junior college and

more

\begin{tabular}{lcccc}
\hline $\begin{array}{l}\text { Occupation } \\
\text { Governments }\end{array}$ & 25 & $10(40.0)$ & - & - \\
Enterprises & 27 & $10(37.0)$ & $0.882(0.826)$ & $1.130(0.843)$ \\
Farmers & 198 & $57(28.8)$ & $0.606(0.253)$ & $0.608(0.396)$ \\
Small private & 15 & $5(33.3)$ & $0.750(0.674)$ & $0.648(0.564)$ \\
business & & & & \\
Others & 13 & $5(38.5)$ & $0.938(0.927)$ & $1.339(0.704)$ \\
Retired & 205 & $112(54.6)$ & $1.806(0.171)$ & $1.684(0.297)$ \\
Unemployed & 96 & $31(32.3)$ & $0.715(0.469)$ & $0.734(0.585)$ \\
\hline Area & & & & - \\
Urban & 346 & $165(47.7)$ & - & - \\
Rural & 233 & $65(27.9)$ & $0.424(<0.001)$ & $0.806(0.478)$ \\
\hline Chronic disease & & & & \\
No & 38 & $13(34.2)$ & - & - \\
Yes & 541 & $217(40.1)$ & $1.288(0.473)$ & $1.211(0.629)$ \\
\hline $\begin{array}{l}\text { Insurance utilization } \\
\text { Yes }\end{array}$ & 542 & $217(40.0)$ & & - \\
No & 37 & $13(35.1)$ & $0.811(0.556)$ & $0.804(0.597)$ \\
Per capita income & - & - & $1.026(<0.001)$ & $1.014(0.047)$ \\
(1K RMB) & & & & \\
\hline
\end{tabular}

$O R$, odds ratio from univariate logistic regression.

$\mathrm{aOR}$, adjusted odds ratio from multivariate logistic regression.

prevalence of inpatient treatment is found to be high, with $39.8 \%$ of the surveyed subjects having at least one episode. Illness that leads to inpatient treatment has serious health and financial consequences (19). The observed high prevalence deserves special attention. The illness conditions that led to inpatient treatments are highly correlated with aging. The frequency of different illness observed in this study can assist better distributing healthcare resources.

Inpatient treatments dominatingly happened in grade II and III hospitals. With an average travel distance of $56 \mathrm{~km}$ and a 
TABLE 5 | Multivariate regression analysis of total and out-of-pocket (OOP) cost.

\begin{tabular}{|c|c|c|}
\hline & Total cost $(n=548)$ & OOP cost $(n=508)$ \\
\hline Gender (reference: male) & $-1,623.4(0.561)$ & $-649.1(0.785)$ \\
\hline \multicolumn{3}{|l|}{ Age group (reference: $45-50$ ) } \\
\hline $51-60$ & $2,947.2(0.520)$ & $1,012.6(0.792)$ \\
\hline $61-70$ & $4,130.0(0.359)$ & $1,319.2(0.728)$ \\
\hline$>70$ & $2,771.7(0.581)$ & $382.4(0.928)$ \\
\hline \multicolumn{3}{|c|}{ Marital status (reference: single/divorced/widowed) } \\
\hline Married & $673.5(0.853)$ & $607.1(0.842)$ \\
\hline \multicolumn{3}{|c|}{ Education (reference: no schooling) } \\
\hline Primary & $-359.8(0.929)$ & $-66.9(0.984)$ \\
\hline Junior high & $915.5(0.831)$ & $537.6(0.883)$ \\
\hline Senior high & $11,943.0(0.018)$ & $10,566.4(0.014)$ \\
\hline Junior college and more & $13,637.7(0.048)$ & $6,580.8(0.274)$ \\
\hline \multicolumn{3}{|c|}{ Occupation (reference: governments) } \\
\hline Enterprises & $-2,472.8(0.775)$ & $-1,224.7(0.867)$ \\
\hline Farmers & $10,374.9(0.194)$ & $9,687.1(0.147)$ \\
\hline Small private business & $10,299.4(0.315)$ & $9,689.9(0.262)$ \\
\hline Others & $-5,571.3(0.606)$ & $-6,442.7(0.481)$ \\
\hline Retired & $2,625.7(0.705)$ & $2,880.3(0.617)$ \\
\hline No jobs & $8,889.8(0.253)$ & $9,169.1(0.157)$ \\
\hline \multicolumn{3}{|l|}{ Areas (reference: urban) } \\
\hline Rural & $-7,019.0(0.086)$ & $-5,970.1(0.088)$ \\
\hline \multicolumn{3}{|c|}{ Type of hospital (reference: grade I) } \\
\hline Grade II & $117.5(0.976)$ & $559.7(0.867)$ \\
\hline Grade III & $12,555.3(0.003)$ & $9,002.9(0.010)$ \\
\hline Private & $-6,442.9(0.564)$ & $-8,461.6(0.416)$ \\
\hline \multicolumn{3}{|c|}{ Chronic disease (reference: no) } \\
\hline Yes & $1,022.3(0.846)$ & $913.0(0.835)$ \\
\hline \multicolumn{3}{|c|}{ Insurance utilization (reference: yes) } \\
\hline No & $12,346.0(0.024)$ & $17,375.1(<0.001)$ \\
\hline Per capita income (1K RMB) & $-64.0(0.481)$ & $-57.8(0.443)$ \\
\hline
\end{tabular}

In each cell, estimated regression coefficient ( $p$-value).

high variation, the accessibility to health care is less satisfactory, at least for some subjects. Similar concerns have been raised in the literature (20). Treatment quality was of the most concern for choosing a specific hospital, which is reasonable considering the special nature of inpatient treatment. Accessibility and insurance utilization also play important roles. Under an effective healthcare system, such factors should play minimal roles in healthcare pursuit. Further work is needed to improve accessibility and to reduce the obstacles in using insurance $(11,17)$. The treatment results are dominatingly positive, with only $5.5 \%$ staying the same and $0.7 \%$ getting worse. Inpatient treatment is expensive $(21,22)$. The average gross total and OOP costs are $14.5 \mathrm{~K}$ and 9.3 K RMB, respectively. In the Henan province, the per capita GDP is $24.7 \mathrm{~K}$ RMB. Even though insurance covers a significant amount of cost (5.5 $\mathrm{K}$ on average), the remaining OOP cost is still high and can pose a serious financial burden, which is consistent with the study comparing health expenditure spending with the economic growth in Brazil, Russia, India, China, and South Africa (8). Cost for the majority of episodes was funded by income and savings. However, cost of $20.6 \%$ of the episodes had to be supported by funds from relatives and friends, which causes a long-term financial burden. The healthcare and insurance systems need improvement to alleviate the financial consequences (13). The insurance utilization rate is high, which is different from that reported in some recent studies (11). The subjects had up to six episodes of inpatient treatments, and different episodes had different characteristics. The variations across episodes are associated with multiple factors, especially the characteristics of illness.

Only age and the presence of chronic disease are associated with the frequency of treatment. The positive association for age is reasonable, as the common illness conditions leading to treatment are aging-related. The presence of chronic disease has been adopted as a surrogate for overall health conditions $(11,17$, 20 ), and the observed positive association is consistent with the literature. Other personal and demographic characteristics are not associated with frequency. This observation differs from that in some recent studies $(14,17)$. The result is "positive" in the sense that no less-advantaged group is identified. The difference may be partly attributable to the homogeneity of survey subjects.

Multiple factors contribute to the utilization of grade III hospitals for inpatient treatment. Gender, marital status, and education are found significant. The pursuit of health care is a complex process $(23,24)$. These factors may contribute via a psychological way as well as associate with other factors. It is noted that in marginal analysis, subjects in rural areas are less likely to use grade III hospital (24); in univariate and multivariate analyses, per capita income is significant. Such results may suggest disparity. Grade III hospitals provide the highest quality of care. In this sense, those living in rural and/or with lower income are less advantaged. Meanwhile, the higher inpatient treatment copayments are required for the rural citizens, so they are more likely to drop out of the inpatient treatment than citizens in urban areas (25). The inequalities of health resources and thus treatment gaps in rural and urban areas have also been investigated in China, India, and U.S. in other studies $(26,27)$. Further adjustment of the healthcare and insurance system is needed to eliminate disparity (25).

Health expenditure has been an important topic and been studied in China as well as in many other countries (6-10). In the analysis of cost, education, type of hospital, and insurance utilization are significant. The significant association for education is partly confounded by the type of hospital used. The high cost of grade III hospitals is associated with the high quality of care. It may also be correlated with the severity of illness. Unfortunately, such information cannot be obtained from survey. Medical records from hospitals have to be collected and analyzed. A small number of subjects did not use insurance in their inpatient treatments. Under the present system, insurance utilization is not automatic, and recent studies have found that there are still a small number of patients who had but did not use insurance (11). The survey did not collect information on why insurance was not used, and thus, further analysis is not conducted (17). However, in spite of the high insurance utilization in inpatient treatment in our study, it may not implicate satisfactory outcomes (28), and thus calls for more attention in the further study.

This study has limitations. To collect certain specific information (for example, the prevalence of inpatient treatment, amount 
of lost income, etc.), survey was used. Survey data have limitations, including possible recall bias and limited information (29). More detailed information on illness, treatment, and outcome has to be obtained from hospitals. As the surveyed subjects used quite a few different hospitals, collecting hospital data is not feasible. When selecting samples, we strived to achieve randomness and representativeness. We have examined data in multiple ways, and there is no obvious sign of sampling bias. However, without having access to more detailed data on the surveyed areas, we are not able to fully confirm representativeness. With limited resources, sample collection was limited to the Henan province, which is representative of Central China. Health conditions and health care vary significantly in China (30). A counterpart study in other areas is also of interest.

\section{CONCLUSION}

This study has provided an updated and comprehensive description of inpatient treatment for the middle-aged and elderly in Central China. It has been found that inpatient treatment has a high prevalence. Its characteristics, age, and the presence of chronic disease are significantly associated with the number of inpatient treatments. The findings can assist healthcare providers to better reform the system. Multiple factors are identified as associated with grade III hospital utilization and cost. Policy

\section{REFERENCES}

1. Wagstaff A, Yip W, Lindelow M, Hsiao WC. China's health system and its reform: a review of recent studies. Health Econ (2009) 18(S2):S7-23. doi:10.1002/hec.1518

2. Yip WC-M, Hsiao WC, Chen W, Hu S, Ma J, Maynard A. Early appraisal of China’s huge and complex health-care reforms. Lancet (2012) 379(9818):83342. doi:10.1016/S0140-6736(11)61880-1

3. Zhao Y, Kang B, Liu Y, Li Y, Shi G, Shen T, et al. Health insurance coverage and its impact on medical cost: observations from the floating population in China. PLoS ONE (2014) 9(11):e111555. doi:10.1371/journal.pone.0111555

4. Cao Q, Shi L, Wang H, Dong K. Report from China: health insurance in China - evolution, current status, and challenges. Int J Health Serv (2012) 42(2):177-95. doi:10.2190/HS.42.2.b

5. Jiang Y, Wang Y, Zhang L, Li Y, Wang X, Ma S. Access to healthcare and medical expenditure for the middle-aged and elderly: observations from China. PLoS ONE (2013) 8(5):e64589. doi:10.1371/journal.pone.0064589

6. Kovacevic A, Rancic N, Segrt Z, Dragojevic-Simic V. Pharmaceutical Expenditure and burden of non-communicable diseases in Serbia. Front Pharmacol (2016) 7:373. doi:10.3389/fphar.2016.00373

7. Jakovljevic MB, Milovanovic O. Growing burden of non-communicable diseases in the emerging health markets: the case of BRICS. Front Public Health (2015) 3:65. doi:10.3389/fpubh.2015.00065

8. Jakovljevic M, Potapchik E, Popovich L, Barik D, Getzen TE. Evolving health expenditure landscape of the BRICS nations and projections to 2025. Health Econ (2016). doi:10.1002/hec.3406

9. Jakovljevic M. Commentary: patient cost sharing and medical expenditures for the elderly. Front Pharmacol (2016) 7:73. doi:10.3389/fphar.2016.00073

10. Jakovljevic MB. BRIC's growing share of global health spending and their diverging pathways. Front Public Health (2015) 3:135. doi:10.3389/ fpubh.2015.00135

11. Wang Y, Jiang Y, Li Y, Wang X, Ma C, Ma S. Health insurance utilization and its impact: observations from the middle-aged and elderly in China. PLoS ONE (2013) 8(12):e80978. doi:10.1371/journal.pone.0080978

12. Ma Y, Zhang L, Chen $\mathrm{Q}$. China's new cooperative medical scheme for rural residents: popularity of broad coverage poses challenges for costs. Health Aff (2012) 31(5):1058-64. doi:10.1377/hlthaff.2009.0808 interventions are needed to make hospitals more accessible and more affordable.

\section{AUTHOR CONTRIBUTIONS}

All the authors contributed to the study design. YJ, YW, YL, $\mathrm{YZ}$, and XW conducted the survey and data collection. YW and YZ conducted statistical analysis. YZ, CM, and SM drafted the manuscript. The final manuscript was read and approved by all authors.

\section{ACKNOWLEDGMENTS}

The authors thank all survey staff and participants for their contributions.

\section{FUNDING}

This work was supported by Yale MacMillan Center Faculty Research award; Renmin University of China Scientific Research Project Funding: Policy Evaluation of Pension and Medical and Social Security in China (12XNI003); National Social Science Foundation of China (13\&ZD164); and the MOE Project of Key Research Institute of Humanities and Social Sciences at Universities (16JJD910002).

13. Li Y, Wu Q, Xu L, Legge D, Hao Y, Gao L, et al. Factors affecting catastrophic health expenditure and impoverishment from medical expenses in China: policy implications of universal health insurance. Bull World Health Organ (2012) 90(9):664-71. doi:10.2471/BLT.12.102178

14. Fang K, Shia B, Ma S. Health insurance coverage and impact: a survey in three cities in China. PLoS One (2012) 7(6):e39157. doi:10.1371/journal. pone.0039157

15. Liang X, Guo H, Jin C, Peng X, Zhang X. The effect of new cooperative medical scheme on health outcomes and alleviating catastrophic health expenditure in China: a systematic review. PLoS One (2012) 7(8):e40850. doi:10.1371/journal. pone. 0040850

16. Shi W, Chongsuvivatwong V, Geater A, Zhang J, Zhang H, Brombal D. Effect of household and village characteristics on financial catastrophe and impoverishment due to health care spending in Western and Central Rural China: a multilevel analysis. Health Res Pol Syst (2011) 9(1):1. doi:10.1186/1478-4505-9-16

17. Nguyen KT, Khuat OTH, Ma S, Pham DC, Khuat GTH, Ruger JP. Impact of health insurance on health care treatment and cost in Vietnam: a health capability approach to financial protection. Am JPublic Health (2012) 102(8):1450-61. doi:10.2105/AJPH.2011.300618

18. A Hierarchical Approach to Hospital Management. Available from: http://baike. baidu.com/view/1429004.htm?func=retitle (accessed September 29, 2014).

19. Moreno-Serra R, Wagstaff A. System-wide impacts of hospital payment reforms: evidence from Central and Eastern Europe and Central Asia. J Health Econ (2010) 29(4):585-602. doi:10.1016/j.jhealeco.2010.05.007

20. Elwell-Sutton TM, Jiang CQ, Zhang WS, Cheng KK, Lam TH, Leung GM, et al. Inequality and inequity in access to health care and treatment for chronic conditions in China: the Guangzhou Biobank Cohort Study. Health Policy Plan (2013) 28(5):467-79. doi:10.1093/heapol/czs077

21. Wang Y, Wang J, Maitland E, Zhao Y, Nicholas S, Lu M. Growing old before growing rich: inequality in health service utilization among the mid-aged and elderly in Gansu and Zhejiang provinces, China. BMC Health Serv Res (2012) 12(1):1. doi:10.1186/1472-6963-12-302

22. Wang S, Liu L, Li L, Liu J. Comparison of Chinese inpatients with different types of medical insurance before and after the 2009 healthcare reform. BMC Health Serv Res (2014) 14(1):1. doi:10.1186/1472-6963$14-443$ 
23. Yang S-H, White RW, Horvitz E. Pursuing insights about healthcare utilization via geocoded search queries. Proceedings of the 36th International ACM SIGIR Conference on Research and Development in Information Retrieval: 2013. Dublin (2013). p. 993-6.

24. Fu R, Wang Y, Bao H, Wang Z, Li Y, Su S, et al. Trend of urban-rural disparities in hospital admissions and medical expenditure in China from 2003 to 2011. PLoS One (2014) 9(9):e108571. doi:10.1371/journal.pone. 0108571

25. Jian W, Chan KY, Reidpath DD, Xu L. China's rural-urban care gap shrank for chronic disease patients, but inequities persist. Health Aff(2010) 29(12):218996. doi:10.1377/hlthaff.2009.0989

26. Patel V, Xiao S, Chen H, Hanna F, Jotheeswaran A, Luo D, et al. The magnitude of and health system responses to the mental health treatment gap in adults in India and China. Lancet (2017) 3074-84. doi:10.1016/S0140-6736(16)00160-4

27. Damien P, Lanham HJ, Parthasarathy M, Shah NL. Assessing key cost drivers associated with caring for chronic kidney disease patients. BMC Health Serv Res (2016) 16(1):690. doi:10.1186/s12913-016-1922-4

28. Leland NE, Fogelberg DJ, Halle AD, Mroz TM. Occupational therapy and management of multiple chronic conditions in the context of health care reform. Am JOccup Ther (2017) 71(1):7101090010p1-7101090010p6. doi:10.5014/ajot.2017.711001

29. Lu C, Chin B, Li G, Murray CJ. Limitations of methods for measuring outof-pocket and catastrophic private health expenditures. Bull World Health Organ (2009) 87(3):238D-44D. doi:10.2471/BLT.08.054379

30. Mu R. Regional disparities in self-reported health: evidence from Chinese older adults. Health Econ (2014) 23(5):529-49. doi:10.1002/hec.2929

Conflict of Interest Statement: The authors declare that the research was conducted in the absence of any commercial or financial relationships that could be construed as a potential conflict of interest.

Copyright (c) 2017 Jiang, Wang, Li, Zhang, Zhao, Wang, Ma and Ma. This is an open-access article distributed under the terms of the Creative Commons Attribution License (CC BY). The use, distribution or reproduction in other forums is permitted, provided the original author(s) or licensor are credited and that the original publication in this journal is cited, in accordance with accepted academic practice. No use, distribution or reproduction is permitted which does not comply with these terms. 